\title{
Evaluation of Unit Canteen Suppliers Based on Entropy Method and Analytic Hierarchy Process
}

\author{
Fu Mian ${ }^{1}$, Wang Dandan ${ }^{1}$ \\ ${ }^{1}$ Anhui Xinhua College Business School
}

\begin{abstract}
With the selection of canteen suppliers as the research object, a canteen supplier evaluation indicator system with four primary indicators and 15 secondary indicators is established in this paper by analyzing the key factors influencing the selection of canteen supplier. At the same time, a case study of four food suppliers of a unit canteen in Hefei, Anhui Province is conducted by comprehensive use of analytic hierarchy process (AHP) and entropy weight method, and some relevant countermeasures and suggestions are proposed.
\end{abstract}

\section{Introduction}

As a daily eating place for unit employees, canteen is an important standard to evaluate the management level of a unit. Employees have higher and higher requirements for diet, and the unit's hardware strength is also constantly developing, so canteen has become a common concern of the staff. Nowadays, unit canteens mostly purchase agricultural and sideline products in the form of bidding, so how to make a correct evaluation on the suppliers of agricultural and sideline products has become a key problem ${ }^{[1-4]}$.

\section{Construction of Evaluation Indicator system of Unit Canteen}

\subsection{Basic Principles for Establishing an Evaluation Indicator system}

Constructing a reasonable indicator system is the basic premise of the objective evaluation of canteen suppliers. In the process of selecting evaluation indicators, it is necessary to take full account of the large demand for food in the unit canteen, and at the same time, food has the uniqueness such as perishability. The specific principles are as follows:

(1) Pertinence Principle

Safety is the primary consideration for canteen food, so it is important to consider the safety, such as the safety of processing conditions and storage conditions, when establishing the canteen supplier evaluation indicator system.

(2) Principle of Qualitative and Quantitative Combination
In order to ensure the rationality and validity of canteen supplier evaluation, qualitative and quantitative indicators cannot be used alone, but should be combined to reflect the whole situation of suppliers comprehensively and accurately. At the same time, in order to carry out the evaluation smoothly, the selected qualitative indicators should be easily quantified.

(3) Operability Principle

It is necessary to consider both the operability and the feasibility of the indicators when selecting the evaluation indicators, and the indicators without operability can be ignored to ensure that such indicators can facilitate the implementation of the evaluation.

(4) All-rounded Principle

With the continuous development of society and economy, and the continuous change in people's consumption demand, the evaluation of the canteen suppliers of agricultural and sideline products should also be constantly changed. The the focus should not only be limited to the production capacity and service, and the ability to innovate is also very important, which is related to the development prospects of suppliers.

\subsection{Construction of Evaluation Indicator System}

Based on the results of previous studies on the evaluation system of canteen suppliers, the evaluation indicator system for canteen supplier selection is constructed from four aspects: product quality, product price, service capacity and production capacity, and four secondary indicators, 4 secondary indicators and 15 tertiary indicators are selected to form the evaluation indicator system, as shown in figure 1. 


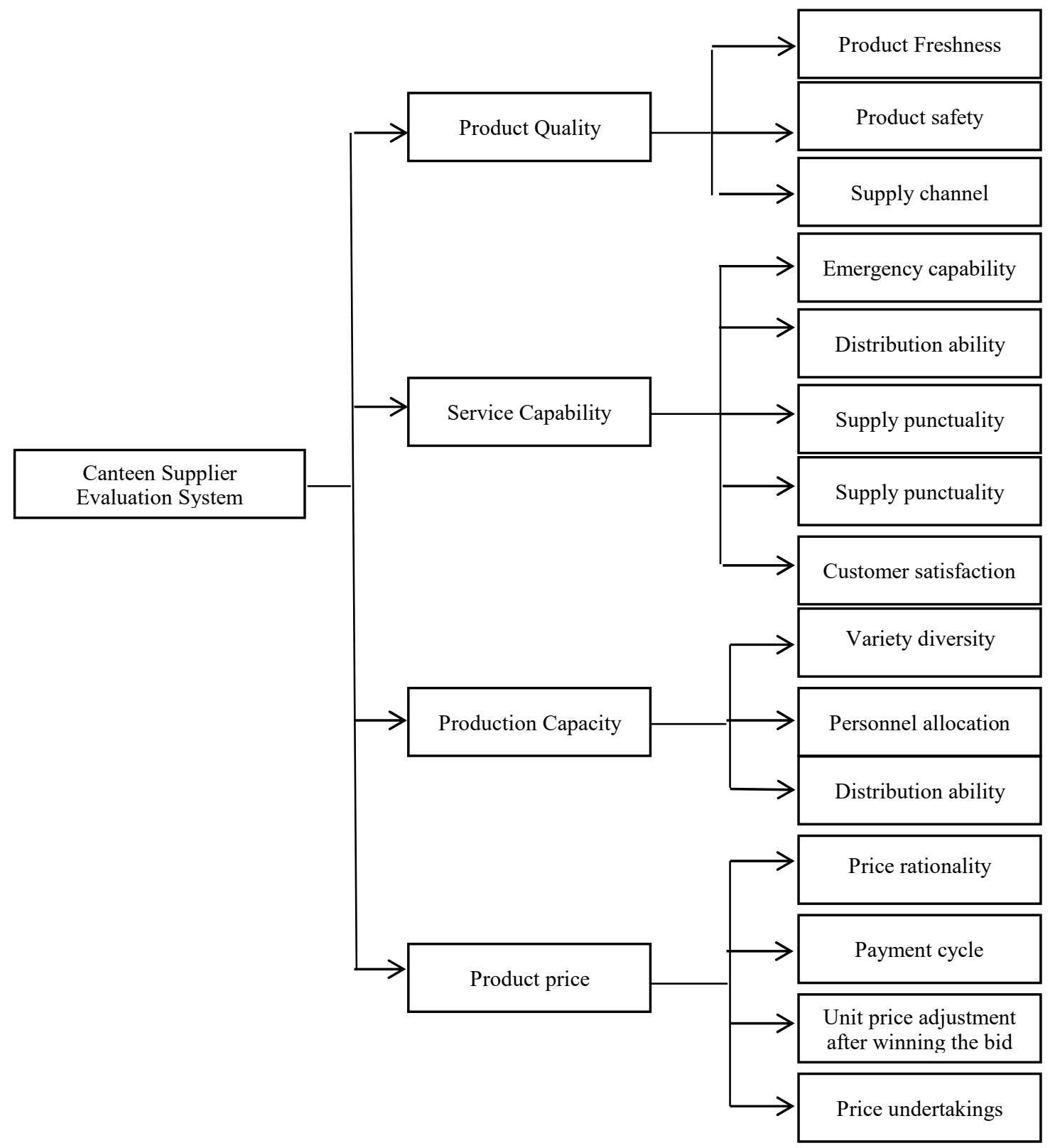

Fig1. Canteen Supplier Evaluation Indicator System

(1) Product Quality

Product Quality is closely linked to enterprise development. Throughout China and foreign countries, every successful enterprise must be inseparable from its excellent product quality. In particular, the product quality of suppliers of agricultural and sideline products is directly related to the life health of consumers, so the quality indicator is decisive in the evaluation of suppliers.

(2) Product Price

The product price determines the cost of unit canteen in purchasing agricultural and sideline products, and the price will have a direct impact on the selling price of the final product. It is closely linked with the operating cost of the unit canteen, and is one of the most basic of all indicators.

(3) Production Capacity

The production capacity of suppliers directly affects the normal operation of enterprises and units. Without sufficient production capacity, the supplier will be difficult to meet the supply needs of enterprises, which will directly hinder the operation of enterprises.

(4) Service Capability

In the current environment, how to do a good job in service has also become a point influencing supplier competitiveness. The quality and level of service will have a direct impact on the stability of the cooperative relationship and business expansion in the local market.

\section{Evaluation of Canteen Suppliers}

\subsection{Determination of Evaluation Indicators Based on the Analytic Hierarchy Process}

The Analytic Hierarchy Process (AHP) is a theory of operational research put forward by Saaty, an American operation research expert and a professor at the University of Pittsburgh, in the 1970s, and it is an analytical method 
based on hierarchical weight decision. The AHP is suitable for solving multi-objective, unstructured and complex decision-making problems. The basic principles are: to make a complex problem hierarchical, and make the process mathematical with less quantitative information, compare the indicators at the same hierarchy by combining quantitative analysis with qualitative analysis to establish a comparison matrix and judge its contribution rate to the indicators of the previous hierarchy, and so on, so that the weight value of each indicator can be finally obtained through the comparative analysis of each hierarchy.

The assignment of the index weight in the evaluation model with AHP can be roughly divided into the following steps:

(1) To divide the complicated problem into hierarchies, and establish the hierarchical structure model

Firstly, the related factors of complex target problems are decomposed into secondary indicators and tertiary indicators, and these three structures are called target hierarchy, criterion hierarchy and indicator hierarchy respectively.

(2) To establish a comparison judgment matrix

The determination of the importance of various indicators at each hierarchy needs to use the consistent matrix method proposed by Saaty et al., which compares two indicators rather than comparing all indicators together; the comparison judgment matrix is a comparison of the relative importance of the indicators at the hierarchy to an indicator at the previous hierarchy. The element $\mathrm{a}_{\mathrm{ij}} \mathrm{in}$ the comparison judgment matrix usually uses Saaty's 1-9 scale method.

(3) To calculate the weight vector and conduct the consistency check

The feature vector and the largest eigenvalue of each comparison judgment matrix is calculated, and then the consistency check is carried out by using the consistency indicator, consistency ratio and random consistency indicator. If the consistency test is successful, its feature vector is the weight vector; if the consistency test fails, it is necessary to rebuild the comparison judgment matrix to test the consistency ratio of the matrix, so as to judge whether the result of indicator weight calculated by AHP is reasonable or not.

(4) To calculate the weight of each indicator

There are two methods to calculate the weight of the comparison judgment matrix: sum method and root method, that is, normative column average method and geometric average method. In this paper, the normative column average method is used to calculate the weight value of each indicator.

\subsection{Determination of Evaluation Indicator Weight Based on Entropy Weight Method}

The entropy method determines the objective weight of each indicator according to its variability. The value of indicator entropy reflects the role of the indicator in comprehensive evaluation. The larger the entropy, the smaller the weight, and the smaller the entropy, the larger the weight. The main calculation steps of the entropy method are as follows:

Suppose there are $\mathrm{n}$ alternatives $\mathrm{U}=\left\{\mathrm{X}_{1}\right.$, $\left.\mathrm{X}_{2, \ldots}, \mathrm{X}_{\mathrm{n}}\right\}(\mathrm{i}=1,2, \ldots \mathrm{n})$ and $\mathrm{m}$ indexes $\mathrm{Q}=\left\{\mathrm{P}_{1}\right.$, $\left.\mathrm{P}_{2, \ldots}, \mathrm{P}_{\mathrm{m}}\right\}(\mathrm{j}=1,2, \ldots \mathrm{m})$. Set $\mathrm{y}_{\mathrm{ij}}$ as the attribute value of the indicator $\mathrm{P}_{\mathrm{j}}$ corresponding to the scheme $\mathrm{X}_{\mathrm{i}}$. As the dimensions of each indicator are different, the decision matrix should be normalized before making a decision, and the normalization matrix $\mathrm{R}=\left(\mathrm{r}_{\mathrm{ij}}\right)_{\mathrm{m}{ }_{\mathrm{n}}}$ (dimensionless) can be obtained.

$$
\mathrm{r}_{\mathrm{ij}}=\frac{\mathrm{y}_{\mathrm{ij}}}{\sqrt{\sum \mathrm{y}_{\mathrm{ij}}^{2}}}(1 \leq i \leq n, 1 \leq j \leq m)
$$

According to the formula, the entropy of the indicator $h_{j}$ is calculated as follows:

$$
\begin{array}{r}
\mathrm{h}_{\mathrm{j}}=-\mathrm{k} \sum_{i=1}^{n} f_{i j} \ln \left(f_{i j}\right) \\
\text { Wherein, } f_{i j}=\frac{\mathrm{r}_{\mathrm{ij}}}{\sum_{\mathrm{i}=1}^{n} \mathrm{r}_{\mathrm{i} j}}, \frac{1}{\ln \mathrm{m}}
\end{array}
$$

And finally, the indicator weight $\beta_{\mathrm{j}}$ is calculated according to the formula as follows:

$$
\beta_{j}=\frac{1-\mathrm{h}_{\mathrm{j}}}{\sum_{\mathrm{j}=1}^{\mathrm{m}}\left(1-\mathrm{h}_{\mathrm{j}}\right)}
$$

Wherein, $0 \leq \beta_{\mathrm{j}} \leq 1, \sum \beta_{\mathrm{j}}=1$.

\section{A Case Study of Canteen Supplier Evaluation}

A unit needs to invite tenders for canteen suppliers for canteen catering to its employees, and now three units have responded to the bidding documents. The content of evaluation includes supplier's qualification, product inspection and quarantine report, product quotation, performance of canteen in state-owned institutions in the past three years, customer service, comprehensive strength and commitment. The supplier evaluation indicator model of the unit canteen was established and the weight of each indicator was determined by combining the management experience according to theISO9000 quality system. Among the three enterprises, enterprise A is a long-established enterprise with large scale and strong production capacity; enterprise B is a small enterprise with relatively favorable price; and enterprise $\mathrm{C}$ improves the quality of supplies and actively promote the level of service with the cold chain logistics and internet + technology.

In order to make the weight of the indicator obtained more scientific and reasonable, the combination of entropy method and AHP was adopted in this paper to arithmetically average the indicator weight value obtained to get the final weight value of the indicator.

First, the AHP was adopted to establish a fourindicator judgment matrix at the first hierarchy, as shown in Table 1 . 
Table1. Index Judgment Matrix

\begin{tabular}{c|c|c|c|c}
\hline & Product Quality & Product Price & $\begin{array}{c}\text { Production } \\
\text { Capacity }\end{array}$ & $\begin{array}{c}\text { Service } \\
\text { Capability }\end{array}$ \\
\hline Product Quality & 1 & 3 & 5 & 5 \\
Product Price & $1 / 3$ & 1 & 3 & 2 \\
Production Capacity & $1 / 5$ & $1 / 3$ & 1 & $1 / 2$ \\
Service Capability & $1 / 5$ & $1 / 3$ & 2 & 1 \\
\hline
\end{tabular}

Due to the limitation of space, the calculation process will not be enumerated one by one. The result was directly calculated through the AHP software yaahp, and then the weight value of the indicator was calculated by the entropy method according to the previous steps, and the result of AHP was arithmetically averaged to obtain the final weight value of the indicator, as shown in Table 2.

Table2. Weight of Supplier Evaluation Indicators

\begin{tabular}{|c|c|c|c|}
\hline Indicator & Weight & Indicator & Weight \\
\hline Product quality & 0.535 & Distribution ability & 0.0834 \\
\hline Service capability & 0.124 & Supply accuracy & 0.083 \\
\hline Production capability & 0.096 & Supply punctuality & 0.101 \\
\hline Product price & 0.135 & Customer satisfaction & 0.062 \\
\hline Product Freshness & 0.111 & Variety diversity & 0.054 \\
\hline Product safety & 0.102 & Personnel allocation & 0.058 \\
\hline Supply channel & 0.088 & Distribution capability & 0.062 \\
\hline Emergency capability & 0.069 & Price rationality & 0.087 \\
\hline Payment cycle & 0.054 & Unit price adjustment after & 0.004 \\
& & & \\
\hline Prinning the bid & \\
\hline
\end{tabular}

Next, the fuzzy and comprehensive evaluation method was used to determine the evaluation results. Twenty members from heads of food and beverage companies, heads of purchasing centre and representatives of canteen were invited to form an evaluation team, and gave the evaluation values using a five-level hundred-mark system, which are excellent (90-100 points), good (70-90 points), medium (50-70 points), general (20-50 points), poor (0-20 points) respectively, to evaluate all secondary indicators of three canteen suppliers participating in the bidding, then the weighted average was used to calculate the final score of each supplier to get the comprehensive ranking: $\mathrm{C}>$ $\mathrm{B}>\mathrm{A}$. It is not difficult to see from the weight that quality, price and service are still the factors most concerned by the unit canteen in the evaluation and selection of suppliers of agricultural and sideline products supplier. Enterprise $\mathrm{C}$ is more advantageous in this aspect.

\section{Conclusion}

Based on the data characteristics and evaluation requirements of existing canteen suppliers, a total of 15 specific indicator factors were selected to establish a supplier selection and evaluation model; three enterprise suppliers were evaluated through the application of the AHP and entropy method. According to the evaluation results, selecting the indicators for evaluating suppliers of agricultural and sideline products can effectively evaluate the source of agricultural and sideline products and the whole quality and safety mechanism of the suppliers, so as to find the weak links of agricultural and sideline products suppliers, and help suppliers to improve the supply chain of agricultural and sideline products.

\section{Author:}

Dr. Mian Fu (1978- ) (Female), is an associate professor from Lu'an, Anhui Province, China, whose major is system modeling and simulation;

E-mail: fm15395112646@126.com; Tel: 15395112646;

\section{Acknowledgments}

This work was supported by Anhui Xinhua university Comprehensive reform pilot project of logistics management under Grant No.2016zy068 and 2018 university level scientific research project of Quality Education Research Center for college students of Anhui Xinhua University under Grant No.IFQE201819 and 2019 Anhui University Humanities and social sciences research project under Grant No.SK2019A0728. The corresponding author of the article is Wang Dan-dan.

\section{Reference}

1. Gu Yanjing. Research on service quality evaluation and promotion strategy of third party logistics based on e-commerce [J]. Value engineering, 2017 (29): 27 29

2. Qiu Li. Construction of logistics distribution service 
quality evaluation system under B2C mode based on fuzzy analytic hierarchy process $[\mathrm{J}]$. Logistics technology, 2017 (6): 6-11

3. Amorim P, Almada-Lobo B. The impact of food perishability issues in the vehicle routing problem $[\mathrm{J}]$. Computers \&amp; Industrial Engineering, 2014, 67(1):223-233.

4. Zou Y F, Xie R H, Liu G H. Safety reliability optimal allocation of food cold chain.[J].Agricultural Sciences, 2013, 04(9):70-75. 